\title{
Proposal for the risk management implementation phase in oil field development project by adding value on the refurbishment of critical equipment
}

\author{
Abdul Hamid ${ }^{1,2, *}$, Ishak Bin $\mathrm{Baba}^{1}$, and Winardi Sani ${ }^{1}$ \\ ${ }^{1}$ Faculty Technology Engineering Universiti Tun Hussein Onn Malaysia, 86400 Johor, Malaysia \\ ${ }^{2}$ Faculty Engineering, Mechanical Engineering Department, Universitas Batam, 29464 Indonesia
}

\begin{abstract}
Refurbishment process is a conceptual stage in product life cycle. It is utilized in existing equipment in the field by adding value to recondition and repaired equipment. The main interest of this paper is to implement and design risk management implementation phase in oil field development project on the refurbishment of critical equipment in oil and gas industry. This paper is provided base on research and experiences in risk management and learned from practical team in industry which matched by an application in oil field development project in refurbishment of critical equipment. A framework of implementation phase for risk management in oil field development project in refurbishment critical equipment were reviewed and added value on communication skills of the project team to the stakeholder and organization, which support to external body and vice-versa. Risk management framework can be used for reference of refurbishment process with simply process and developed with same concept for the next wide development project in industry.
\end{abstract}

\section{Introduction}

Refurbishment process is a conceptual stage in product life cycle. Oil field equipment (OFE) such as tooling can be reconditioned after it is used in market. Performing the refurbishment process is to utilize the existing equipment in the field to determine the product cycle and sustainability [1]. Complete refurbishment of OFE equipment can eliminate waste along with the product used. These processes of refurbishment is similar to produce new OFE and depending of order scope, purchase order and contract but no limit for rental tool and equipment. Repair and remanufacture shall be complied with API spec $6 \mathrm{~A}$ if it's an original equipment manufactured in accordance to the API international standard during lifecycle for continues service by user [2]. Many OFE Manufacturing companies in Batam Island Indonesia have operated refurbishment role and rent equipments and tools to support their organization survival and growth.

* Corresponding author: gn150003@siswa.uthm.edu.my 
The traceability is important and shall be complied with standard requirement of API Spec 6A to increase profitability and compliance [2]. If it is not tracked properly and / or loose traceability, this will cause loosing an expensive drill and become cost prohibitive [3]. It is identified earlier to manage the traceability of the product during manufacturing process until delivered to field/hand over to client.

A risk is likelihood of specific consequence happening [4,5]. Refurbishment of OFE will potentially face more issue and risk in technical, quality, and economical uncertainty and more risk than new product scheme. Risk management is recognized as an integral part of a good management practice. Based on ISO 31000 as mentioned that a successful risk management initiative shall be proportionate to the all level of risk in organization, aligned with other corporate activities, comprehensive in its scope, embedded into routine activities and dynamic by being responsive to changing circumstances" [6].

\section{Objectives}

The aim of risk management is to obtain understanding by all parties in an organization and agreed on that can be risk really managed and improved through early detection and mitigation on product life cycle management such as remanufacture and refurbishment project. The objective of this paper is to propose risk management implementation phase in oil field development project by adding value on refurbishment product. The main interest of this paper is to review current method in the area of risk in refurbishment project and reflecting to risk and greenality.

\section{Method approach}

This paper is conducted based on research and experiences into risk management its potential to prevent and eliminate risk and learning from performance team in industry which matched by an application in project refurbishment in Batam manufacturing Indonesia.

\subsection{Evaluating a risk management (Review and industry standard study)}

OFE refurbishment requires more technical and economic uncertainty and risk [7]. Rush on delivery and limited time given is a risk. It is changing with project scope frequently and size of the project and the decision making process is hampered by the lack of clear in communication within client and manufacturer and definition can change a cost and profitability. Specific areas for risk management of conservation refurbishment project includes:

Design constrains. Varying an OFE and tools of level specification couple with restricted component and material selection has different risk implication [7]. A creativity Engineer and PM team to substitute material and focus on technical problem resolution rather than consider risk in systematic manner [8]. Poor design can cause of time delivery, cost and quality achievement and then expertise person is required to focused on resolution for project constrains [9]

Stakeholders and involvement external bodies. There are enhanced communication risk ranging from different area of expertise and between different corporate structure and culture and line communication between stakeholders may require different frame and task. The available ability of the professional team member with requisite experience or expertise at particular project time during project period. Invention from external bodies 
from various statutory bodies and any group it's potentially imposing expensive mandatory requirement or major restrictions upon the program work and this risk shall be evaluated at early project stage.

Manufacturing load/capacity. When a refurbishment OFE deal with project/stakeholder and sales with clearly scope and defined of area re-pair or remanufacturer than schedule and planning shall have capacity in plant. A risk can be identified by PM for any opportunity slot in and any project constrains face on high load capacity during the period of refurbishment schedule. Lack of communication and control the project has a risk to deliver it as per desire schedule and requirement.

Supply chain management (SCM). Several spare parts and material are quite difficult to supply with limited sources and lead time. High demand material and dependence on supplier or vendor make a manufacturer at a high risk [10]. Assessment to this SCM role for refurbishment OFE would be important to implement. The refurbishment project orientation in supply management which is a manufacturer face on adversity and deeper risk management culture and applied project management techniques to greater focus on risk management [10].

The OFE development project in the refurbishment critical equipment is a systematic process as suggested on API spec 6A for re-manufacturing annex $\mathrm{H}$ [2]. Figure 1 is the general Christmas tree assembly as critical equipment in the well field.

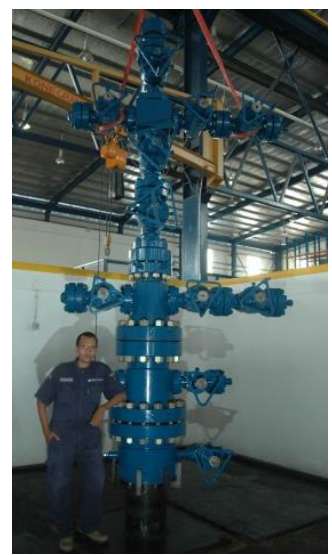

Fig. 1. Typical Christmas tree nomenclature as API license manufacturer [2].

Typical Christmas tree nomenclature as shown in figure 1 is used to control well production that consist of assembly of equipment including tubing head (bonnet), valves, tees, crosses, top connectors and chokes that attached to the uppermost of tubing head [2].

\subsection{The risk management process for refurbishment project (Outline)}

Generally, a project risk management (PRM) has been developed to associate the process model in literature $[11,12]$ :

Plan risk management. It is defining how to conduct risk management activities for refurbishment project. The risk management plan is vital to communicate with an agreement and knowledge supported by all stakeholders to ensure a risk management process is performed effectively over the project life cycle.

Identify risk. Listing all potential impact on the project [13] .It's a process of detection which a risk may be affecting and dangerous forwards the project. The objective is for the 
PM to anticipate event occurred of the risk. Identifying risk is a typical continuous iterative process that cause the risk to exist and identified during project through its life cycle.

Qualitative and quantitative analysis. In practice these are method in nature to further analysis by assessing the probably and impact of the risk and used a numerical data collection. This process is to obtain risk assessment documentation [5].

Risk Prioritization. It can be conducted as long as measurement of priority system is used and taking from qualitative and quantitative risk list into account with rank.

Risk Response. To develop option and action to enhance opportunities and reduce/eliminate a thread to project objectives. This process is following the qualitative and quantitative risk analysis process. Selected the optimum risk response from each option is required to address the risk.

Monitoring risk. It can be monitored along the process in progress. Implementation of risk response plan, tracking the risk and evaluate with risk response. Evaluating implementation risk assessment effectiveness and review to issue a trigger impulse to support make a decision of significant change for risk assessment [12].

\section{Result}

\subsection{Risk management method implementation (by adding value on communication skills)}

The selected method was present from the possibility of refurbishment process of OFE for more focused to the method are used and effort eventually covers the risk management processes. Implementation phase on the risk management in the oil field development project on the refurbishment process can propose to use a framework as shown in Figure 2.

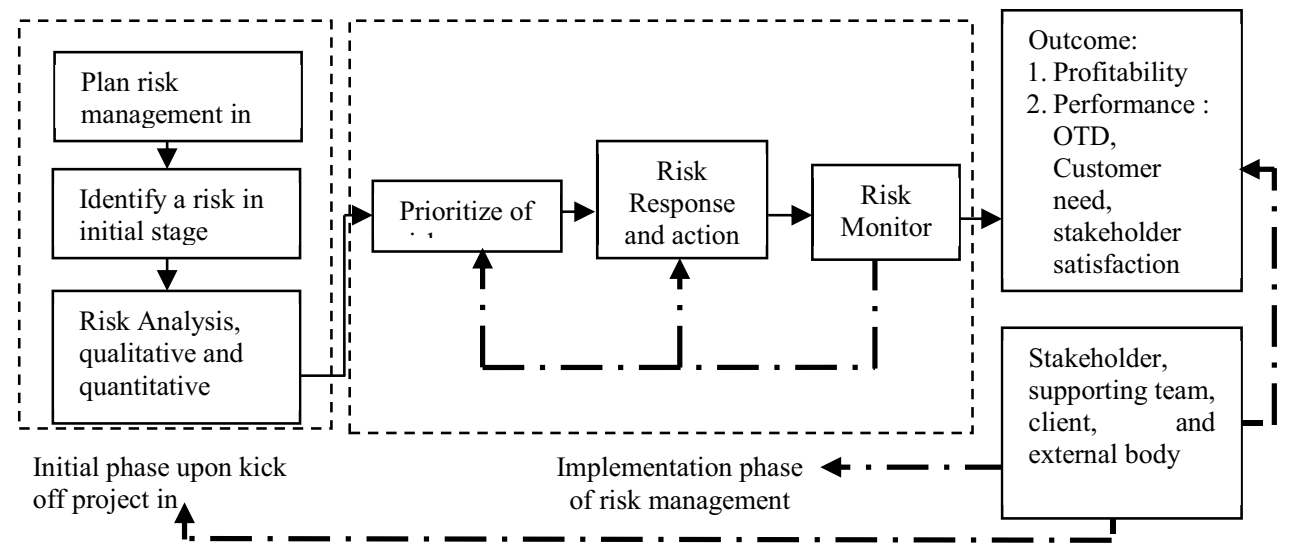

Fig. 2. Framework study to propose implementation phase for risk management oil field development project by adding value on refurbishment product.

Method of risk prioritization. This concept is to describe a probability and impact of risk. On implementation phase of risk management for development OFE development project in refurbishment with base/simple technique such pareto analysis and top 3 or 5 or 10 rank for the risk plan [14].

Method of Risk response and action. A checklist can be use following what an analysis count in risk assessment matrix. Risk assessment is used to measure any probability and impact on matrix grid[15]. It is required an action to prevent any missed and slip following the rank of risk and matrix grid. 
Monitoring risk and feedback. There is a line communication in figure 2, were discussed with review literature and industry standard. Skill up communication is highly recommended to cover following aspect in refurbishment process to complete the task such as improved in engineering and technical aspect includes risk plan, identification, and analysis. Implement effective communication between PM and team to an internal and external organization and manufacturing include logistic and SCM and stakeholder.

\section{Summary}

The necessary implementation phase on risk management for OFE development project in refurbishment of critical equipment Christmas tree has been discussed with taking a literature, industry standard, and experimentally study. It is clear definition that risk can be manage and monitor by adding an action or correction by implement two way communication for stakeholders and PM team. A Risk management framework can be used for reference of refurbishment process with simple process and develop for the next project or development project in OFE manufacturer.

We would like to thank Faculty Engineering Technology UTHM and grateful for industry partner in Batam island and Universitas Batam Indonesia to significant support on this research project.

\section{References}

1. M. Richard, S. David, Green Project Management, (CRC Press NW, 2011)

2. C. API, M. Annex, O.F. Specification for Wellhead and Christmas Tree Equipment, (U.S. National, 2009)

3. S. Tiku, A.F. Veneruso, R.K. Etchells, M. Pecht, Oil Gas SCI. Technol. J., 60(4), 721 (2005)

4. A. Polytechnic, O. Adibo, Anal. Risk Manage. J., 5(29), 139 (2013)

5. A. Ahmed, B. Kayis, S. Amornsawadwatana, An International Journal, 14(1), 22 (2007)

6. Airmic, Alarm, Irm, Risk Manage. J., 7(1), 20 (2010)

7. J. Reyers, J. Mansfield, Struct. Surv. J., 19(5), 238 (2001)

8. J. Bowers, A. Khorakian, Eur. Innov. Manage. J., 17, 25 (2014)

9. N.V. Thuyet, S.O. Ogunlana, P.K. Dey, Oil Gas. Int. Energy. Sect. Manage. J., 1(2), 175 (2007)

10. G.J.L. Micheli, E. Cagno, M. Zorzini, MRN, 31(11), 846 (2008)

11. P. Smith, Managing risk proactively in product development projects, 1 (2002)

12. Project Management Institute, Project Management Body of Knowledge A Guide to the Project Management Body of Knowledge, (2000)

13. Y.H. Park, Asian Qual. J., 11(1), 39 (2010)

14. J. Oehmen, B. Dick, U. Lindemann, W. Seering, Proceedings DESIGN 2006, 9th International Design Conference, (Dubrovnik, Croatia, 2006)

15. H. Zhang, M. Yongbo, International Business and Management, 23(1), 99 (2011) 